\title{
Overview of Mandibular Condyle Fracture
}

\author{
Su-Seong Park ${ }^{1}$, Keun-Cheol Lee ${ }^{2}$, Seok-Kwun Kim² \\ ${ }^{1}$ Nose Plastic Surgery Clinic; ${ }^{2}$ Department of Plastic and Reconstructive Surgery, Dong-A University School of Medicine, Busan, Korea
}

The mandibular condyle is a region that plays a key role in the opening and closing of the mouth, and because fracture causes functional and aesthetic problems such as facial asymmetry, it is very important to perform accurate reduction. Traditionally, there has been disagreement on how to manage fracture of the mandibular condyle. This review explores the misunderstanding of mandibular condyle fracture treatment and modern-day treatment strategies.

\author{
Correspondence: Su-Seong Park \\ Nose Plastic Surgery Clinic, \\ Dong-goong B/D 3F, 26 Bujeon-ro \\ 66beon-gil, Busanjin-gu, Busan \\ 614-847, Korea \\ Tel: $+82-51-804-0007$ \\ Fax: +82-51-804-7794 \\ E-mail: foolx100@naver.com
}

Keywords Mandibular condyle / Mandibular fractures / Surgical procedures

\begin{abstract}
This article was invited as part of a panel presentation, which was one of the most highly rated sessions by participants, at the 69th Congress of the Korean Society of Plastic and Reconstructive Surgeons on November 11, 2011 in Seoul, Korea

No potential conflict of interest relevant to this article was reported.
\end{abstract}

Received: 27 Jun $2012 \bullet$ Revised: 28 Jun 2012 • Accepted: 29 Jun 2012

pISSN: 2234-6163・ elSSN: 2234-6171・ http://dx.doi.org/10.5999/aps.2012.39.4.281・ Arch Plast Surg 2012;39:281-283

Mandibular condyle fracture occurs so frequently that they account for approximately $30 \%$ to $40 \%$ of all mandibular fracture cases, and patients between 25 and 34 years old who have a busy social life account for one third of all the cases. Furthermore, about $40 \%$ of child injury patients have mandibular condylar fracture [1]. The mandibular condyle is a region that plays a key role in the opening and closing of the mouth, and because it causes functional and aesthetic problems such as facial asymmetry, it is very important to perform accurate reduction. While various treatment techniques have been investigated for the recovery of basic functions, occlusion, with regard to the treatment of mandibular condylar fracture, arguments on the course of its treatment continue to this day. Mandibular condylar fracture can generally be treated with open reduction, or conservatively with closed reduction.

Ever since MacLennan [2] advocated closed reduction for 180 cases of mandibular condylar fracture patients in 1952, stating that "complications arising from mandibular condyle fractures are conspicuous by their absence," closed reduction has been the "conventional wisdom" of mandibular condylar fracture reduction for several decades. Blevins and Gores [3], however, after performing conservative treatment in 140 patients, saw good prognosis in only $13 \%$ of the patients, whereas $36 \%$ of the patients were observed to have some problems, and 50\% had a mouth opening measuring only $28 \mathrm{~mm}$. In 1994, Silvennoinen et al. [4] observed limitations in mouth opening in $15 \%$ of the 92 patients in the study that they conducted, and in $17 \%$ of the patients, malocclusion and persistent mandibular deviation occurred during mouth opening. In numerous studies that compared the prognosis of closed reduction with that of open reduction, Eliis et al. [5-7] reported that mild complications such as scarring or partial paralysis of the facial nerve were observed in open reduction while relatively serious complications, including chronic pain, malocclusion, facial asymmetry, and limited mobility, were observed in closed reduction. Based on these recent research findings, open reduction is currently regarded as having

Copyright $($ C 2012 The Korean Society of Plastic and Reconstructive Surgeons

This is an Open Access article distributed under the terms of the Creative Commons Attribution Non-Commercial License (http://creativecommons.org/

licenses/by-nc/3.0/) which permits unrestricted non-commercial use, distribution, and reproduction in any medium, provided the original work is properly cited.

www.e-aps.org 
a better prognosis under appropriate indications and conditions, and the development of radiological diagnosis and surgery techniques is seen as playing a role in viewing such results.

In the early and mid-1900s, when the radiological diagnosis technology was still inadequate, Brophy classified fractures as "through the neck, from above and in front, or backward and downward" according to their location and direction, and Thoma classified them, according to the displacement and the extent of dislocation, as "fracture with/without displacement, dislocation, or dislocation and complete displacement." MacLennan [2] created a classification system based on deviation, displacement, and dislocation, and this system classified mandibular condylar fracture as "high or low, with deviation and displacement, dislocation, no displacement, or avulsion." The classification devised by Lindahl [8] is currently generally used, and it classifies fractures as "head, neck, or subcondyle" depending on the fracture level; as "medial, lateral, no overlap, or fissure" according to the extent of dislocation; and as "no displacement, slight displacement, moderate displacement, or dislocation" according to the location of the condylar head and articular fossa.

Archer [9] made an extreme claim, saying that there is no indication for open reduction because it causes the problems of trismus or ankylosis and sterile or suppurative resorption. Through ongoing research, however, Zide and Kent [10,11] classified the cases requiring open reduction by indication in a relatively objective manner, and this has been useful up to the present. According to Zide [12], in cases with displacement and ramus height instability, either of these two actually become indications of open reduction. In general, if a patient has an acceptable range of motion, good occlusion, and minimal pain, it is ideal to perform observation or closed reduction and maxillomandibular fixation. In the case of displacement or unstable low condylar fracture or subcondylar fracture according to the Lindahl classification, it is ideal to perform open reduction.

The approaches to open reduction include the intraoral, preauricular, submandibular, retromandibular, and rhytidectomy approaches. Although the intraoral approach has the advantage of having no visible scars and minimizing the damage to the facial nerve, it has the drawbacks of having limited access and the inability to sufficiently secure the visual field of the operative site, and using the trocar system for fixation [13]. The preauricular approach is mainly used in high-condylar-fracture cases and is useful for reducing an anteromedially distracted condylar segment, but it poses a risk of nerve injury (3.2\% to $42.9 \%)$, and access to the mandibular angle and ramus is restricted. The submandibular approach is a method of inserting a $1.5-$ to $2-\mathrm{cm}$ incision below the inferior border of the mandible. Although it is useful in lower condylar fracture, there is a risk of nerve injury and a high likeli- hood of scars with incision lengths up to 4 to $5 \mathrm{~cm}$, and because there is a considerable distance between the skin incision site and the fracture site, proficient skills are required on the part of the surgeon. To complement these drawbacks, the retromandibular approach is sometimes used. The rhytidectomy approach was devised by Zide and Kent [10] in 1983. While it has the advantages of having a very good visual field and addressing the problem of facial scarring to some extent, it has the disadvantage of very long closure. Although extracorporeal fixation has the advantage of being capable of condyle height control and of enabling relatively accurate reduction even in complex fractures, there is a risk of developing complications such as avascular necrosis, resorption, and arthrosis. The endoscopic approach is also currently being attempted. Thus far, however, its cost is relatively high, and its surgery time is longer than that of the conventional methods. Moreover, there is not much difference in patient morbidity between this method and the others. Therefore, more research is needed on this matter.

With regard to the method of fixation, while wire was used by ligating it or using a long screw or lag screw, the method of using a plate and a screw is often utilized at present, for better stability. After examining the studies that had been conducted on the use of a plate and a screw for open reduction, Choi et al. [14] published the following results: in a study where a load was applied by fixing one or two miniplates on the in vitro model, the group with two fixed miniplates was more stable than the group with only one fixed miniplate. Throckmorton and Dechow [15] reported that in the experiment that they conducted to measure the in vitro mandibular model, tensile force was applied to the anterior condylar head, and compressive force to the posterior condylar head. In a clinical study on miniplate fixation, Haug et al. [16] compared the zygomatic dynamic compression plate, locking adaptation plate, mini dynamic compression plate, and adaptation plate systems and concluded that mini dynamic compression is the most stable.

The direction of mandibular condylar fracture treatment is to perform active open reduction as often as possible rather than conservative closed reduction, in order to obtain better results. This is significantly due to the advancement of surgery techniques. In the future, further studies must be conducted on how to acquire good prognosis while reducing the complications with regard to open reduction of mandibular condylar fracture.

\section{REFERENCES}

1. Yun SP, Um IW, Lee DK, et al. The clinical study on functional recovery after open reduction ofmandibular fractures. J Korean Assoc Oral Maxillofac Surg 1992;18:9-18. 
2. MacLennan WD. Consideration of 180 cases of typical fractures of the mandibular condylar process. Br J Plast Surg 1952; 5:122-8.

3. Blevins G, Gores RJ. Fractures of the mandibular condyloid process: results of conservative treatment in 140 patients. J Oral Surg Anesth Hosp Dent Serv 1961;19:28-30.

4. Silvennoinen U, lizuka T, Oikarinen K, et al. Analysis of possible factors leading to problems after nonsurgical treatment of condylar fractures. J Oral Maxillofac Surg 1994;52:793-9.

5. Ellis E 3rd, Palmieri C, Throckmorton G. Further displacement of condylar process fractures after closed treatment. J Oral Maxillofac Surg 1999;57:1307-16.

6. Ellis E 3rd, Throckmorton GS, Palmieri C. Open treatment of condylar process fractures: assessment of adequacy of repositioning and maintenance of stability. J Oral Maxillofac Surg 2000;58:27-34.

7. Ellis E 3rd, Simon P, Throckmorton GS. Occlusal results after open or closed treatment of fractures of the mandibular condylar process. J Oral Maxillofac Surg 2000;58:260-8.

8. Lindahl L. Condylar fractures of the mandible. I. Classification and relation to age, occlusion, and concomitant injuries of teeth and teeth-supporting structures, and fractures of the mandibular body. Int J Oral Surg 1977;6:12-21.
9. Archer WH. Oral and maxillofacial surgery. 5th ed. Philadelphia: Saunders; 1975.

10. Zide MF, Kent JN. Indications for open reduction of mandibular condyle fractures. J Oral Maxillofac Surg 1983;41: 89-98.

11. Zide MF. Open reduction of mandibular condyle fractures. Indications and technique. Clin Plast Surg 1989;16:69-76.

12. Zide MF. Discussion: outcomes of open versus closed treatment of mandibular subcondylar fractures. J Oral Maxillofac Surg 2001;59:375-6.

13. Kim BJ, Cha YH, Lim JH, et al. Open reduction of mandibular condyle fracture via preauricular approach. J Korean Assoc Maxillofac Plast Reconstr Surg 2010;32:521-8.

14. Choi BH, Kim KN, Kim HJ, et al. Evaluation of condylar neck fracture plating techniques. J Craniomaxillofac Surg 1999;27:109-12.

15. Throckmorton GS, Dechow PC. In vitro strain measurements in the condylar process of the human mandible. Arch Oral Biol 1994;39:853-67.

16. Haug RH, Peterson GP, Goltz M. A biomechanical evaluation of mandibular condyle fracture plating techniques. J Oral Maxillofac Surg 2002;60:73-80. 